\title{
Research on the development of green food industry in Heilongjiang
}

\author{
province \\ Zhenjia An ${ }^{1, a}$, Li Zhao ${ }^{2, b}$, Lei Wang ${ }^{3, c}$, Feng Guan ${ }^{4, d}$ \\ Harbin University of Commerce, Harbin,China \\ bsjm@hrbcu.edu.cn
}

Keywords: green food; industrial development; influence factors

\begin{abstract}
The green food industry is a new industry which adapts to the current economic development and coordinates with the society and resources. The development of green food industry is an important way to realize the adjustment of agricultural structure, the transformation of economic development mode and the optimization and upgrading of industrial structure. Based on the investigation of the green food industry, the status quo and existing problems of green food are analyzed and summarized, and then the Suggestions for promoting the development of the industry are put forward.
\end{abstract}

\section{Introduction}

China's economy has gradually entered the stage of new normal development. The extensive mode of economic growth alone cannot effectively drive the sustained economic growth, and the path of sustainable development is a long-term solution. China's rural areas have established the economic development strategy of changing the mode and adjusting the structure, paying more attention to the quality of products and the protection of ecological environment. Today's consumers are less sensitive to price and more demanding on product quality. The change of consumer demand has brought unprecedented development opportunities to the green organic food industry.

\section{Industrial development status}

\subsection{Certain scale of industrial development}

The number of green food production enterprises in China is growing and the products are increasingly diverse .Among the green food products in Heilongjiang province, rice, soybean, dairy products and special products stand out as the products with obvious advantages, and have initially formed the rudiment of industrial cluster. Heilongjiang Beidahuang group took the lead in developing the green food industry in 1990, becoming a leader in the development of China's green food industry. Relying on the abundant agricultural products resources and superior location conditions in Heilongjiang province, Beidahuang group has vigorously carried out agricultural production standardization construction, and cultivated a large number of leading enterprises with large production scale, high visibility and strong driving capacity.

\subsection{Product quality is stable and reliable}

Heilongjiang green food industry has established a new view of quality in the field of food production. Increased supervision, improved inspection standards and made food production to a high quality level. Prenatal environmental monitoring and raw materials testing, implementation of specific production and processing operating procedures in production, and postpartum control of 
product quality, health indicators, packaging, freshness preservation, transportation, storage, sales, to ensure the overall product quality of green food.

\subsection{Obvious driving effect of green food export}

Beidahuang group has implemented the export brand strategy, and the foreign trade shows a rapid growth trend, with the total import and export increasing year by year, among which the export shows a rapid growth. The overall strength and competitiveness of the foreign trade operation subjects of Beidahuang group have been generally improved. The enterprise structure has also shifted from a single professional foreign trade company to a self-run production enterprise. At present, a number of enterprises carry out self-run import and export business.

\subsection{Enterprise management is gradually standardized.}

Party organizations at all levels in Heilongjiang province by an special workshop, and other forms, organize the cadres and workers learn more Xi general secretary's important speech at the end of the inspection work in Heilongjiang province, study hard understand the requirement from the provincial government and the ministry of agriculture for agricultural reclamation reform, study and draw lessons from the reform experience of brothers land reclamation area, strengthen confidence, building together. In order to strengthen the supervision and management and regulate the business behavior of enterprises, Heilongjiang province comprehensively uses various measures such as economy, law and administration to strictly implement the responsibility, strengthen the system construction of weak links and gradually standardize the management of enterprises.

\subsection{Form a relatively complete industrial system.}

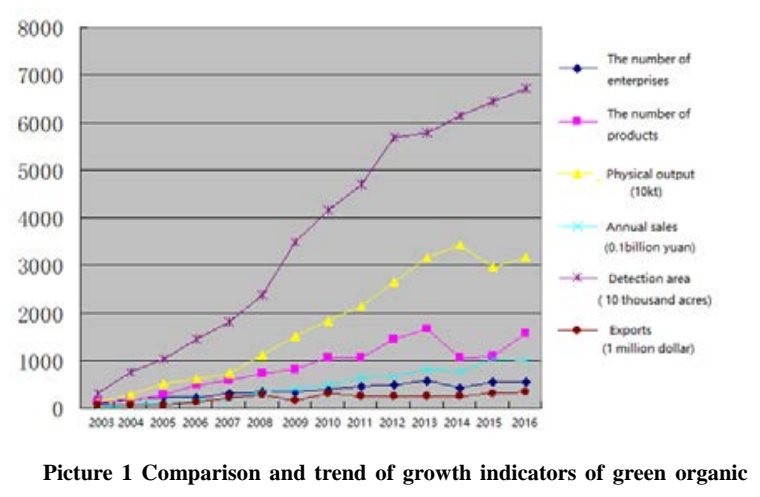

Heilongjiang green organic food industry has formed a relatively complete industrial system linked by base, product and market. The green organic food product category is relatively complete, base size and development level, as well as the industrial development trend of constantly improving market circulation level. The development of green organic food industry in Heilongjiang province is good, with the main indexes maintaining steady growth.(as the picture 1 shows)

\section{Major problems in the development of green food industry}

\subsection{Insufficient industrial concentration}

The majority of green food production and processing enterprises in Heilongjiang province are not distributed in a centralized and decentralized manner, and have not given full play to the spatial cluster effect of green food industry. The leading green food enterprises have not played a leading role in the industrial cluster, and cannot form the cluster effect, scale effect and brand effect centered on core enterprises. Not giving full play to the central effect is not conducive to the sustainable and rapid development of the group's green food industry.

\subsection{Insufficient industrialization capacity}

On the one hand, the production bases of green food in Heilongjiang province are mostly distributed in the group's large farms, with scattered locations and low spatial clustering degree. Communication between the core enterprises and the sub-production bases is also inconvenient, which will lead to the problem of little communication and communication between the production bases and incomplete information transmission. On the other hand, Heilongjiang province's green food enterprises have insufficient scientific research capacity, and enterprises ignore the high added 
value and high income that the refined and processed green products can bring, resulting in low economic benefits.

\subsection{Weak industrial brand influence}

The lack of publicity by Heilongjiang province's green food enterprises has led to less known products .Although Heilongjiang has its own well-known green food brands such as Beidahuang and Wandashan, its management is messy. Many brand publicity methods are single and insufficient, resulting in a lack of adequate market competitiveness, and consumers lack a deep understanding and recognition of the green agricultural brands in Heilongjiang province. At present, Heilongjiang province has several green food enterprises with strong strength, but their brand positioning is unreasonable, which affects the economic profit of green food and limits the research and development of enterprises' production technology.

\subsection{Low scientific and technological content of green food products}

Heilongjiang province has few breakthrough applications, low conversion rate and low efficiency. Up to now, pest control in planting industry and forestry mainly relies on the traditional method of pesticide.Physical techniques for pest control have not made much headway.Low level of product research and development, low technology content, low added value, low efficiency of industrial development.The green food planting in heilongjiang province mainly adopts the primitive farming method, with low production technology level, weak disaster resistance capacity, and low technical content of products.

\subsection{Construction of prenatal raw material production base lags behind}

Raw material base is the source of quality and safety control of agricultural products.In recent years, some small and medium-sized enterprises have been shortsighted in their development. In spite of the infrastructure construction of the production base, they have greatly increased production capacity and lacked the overall planning of the base. As a result, the standardization level of some agricultural production is low.

\section{Selection of strategies for the development of green food industry}

\subsection{Increase the brand construction of green food industry in heilongjiang province}

Increasing the brand construction of green food is an effective way to improve the core competitiveness of enterprise products.It is necessary to strengthen the publicity and advertising of the green food industry, make full use of various media to show the advantages of green food from all aspects and angles, and at the same time, innovate the communication content and form.Seize the opportunity of national brand building to build independent brands.In the process of the gradual growth of enterprises, the industrial structure should be constantly optimized and upgraded, and the advantages of product development, product quality and cultural innovation should be shifted to a higher level, so as to increase the added value of green food.

\subsection{Vigorously promoting the construction of modern agriculture}

Heilongjiang province actively implements general secretary xi jinping's instruction "' to adhere to the direction of developing modern agriculture, strive to be the leader in agricultural modernization, speed up the construction of large bases, enterprises and industries of modern agriculture, and strive to form an aircraft carrier in the agricultural sector" ".We should take the introduction of strategic investors and the development of mixed-ownership economy as the breakthrough point to comprehensively advance the economic system reform of green food enterprises. While introducing funds, we should also increase subsidies to green food producers. We should make full use of the driving role of large green food enterprises to improve the concentration of production and processing enterprises in the green food industry. With modern technology and equipment as 
support, with modern organizational management methods to operate, improve labor productivity and product added value.

\section{3 implement whole-process quality control for the green food industry}

First of all, it should be emphasized that the green food industry comes from the best ecological environment. In the production process, chemical substances such as pesticides, fertilizers and additives are not used, and physical methods of weeding and fertilization are used to follow the natural growth rules of the products to produce green, healthy and pollution-free products. Adopt the production mode of farmer and enterprise, reduce the participation of middlemen, reduce the cost and guarantee the quality of green food. For the processing enterprises of agricultural products, we should emphasize on the management of the production hygiene of the enterprises, and establish and perfect a scientific production system of quality and safety. In the sales link, attention should be paid to logistics transportation and storage of green food, such as temperature and humidity control, prevention of secondary pollution, and prevention of corrosion and mildew. The supervision department should strengthen the quality control supervision, carry on the strict quality authentication, to the green food carries on the overall inspection.

\section{4 improve the scientific and technological content of the green food industry}

To promote the development of green food industry, we need to take scientific development as the theme and speed up the way of industry development. In order to adapt to the new production needs, new agricultural machinery equipment needs to be vigorously supported .We will actively use new technologies to develop water-saving agriculture, control the amount of irrigation water, and reduce the use of fertilizers and herbicides. We should give full play to the supporting and guiding role of the government and industrial administrative departments, and promote technological innovation and progress in industry. At the same time, we should seize the development opportunities in the era of big data to understand the precise sales of green food in various regions and optimize the allocation of resources. In the Internet era, the sales of green food should also be combined with online and offline sales, so as to achieve direct contact between manufacturers and customers, facilitate information communication and improve sensitivity to the market, so as to achieve precision production.

\section{Acknowledgment}

This research was supported by Philosophy and Social Sciences Planning Project in Heilongjiang (No.16JYB14);National undergraduate innovation and entrepreneurship training program(201710240022)

\section{References}

[1] Joris Aertsens,Koen Mondelaers,Wim Verbeke,Jeroen Buysse,Guido Van Huylenbroeck. The influence of subjective and objective knowledge on attitude, motivations and consumption of organic food[J]. British Food Journal,2011,113(11).

[2] Yueping Du,Yilin Wang. Research on Constructing Innovation-Driven Development Evaluation System Based on the Essential Component of Intellectual Property[J]. Open Journal of Business and Management,2017,05(01).

[3] Borrell, Andrew K., Mullet, etal.Drought adaptation of stay-green sorghum is associated with canopy development, leaf anatomy, root growth, and water uptake[J].Journal of Experimental Botany, 2014, 65 (21) : 6251-6263

[4]William A Knudson. The Strategic Marketing Institute Working paper[J].The Organic Market, 
2006 (1) : 432-440.

[5] John Adams. Industrial clusters and regional economic development in China: the case of "green "food[J]. Journal of Chinese Entrepreneurship, 2009, 1(3): 279-294. 